\title{
Knowledge, Attitudes, and Behaviors of Female Teachers Related to Breast Cancer and Breast Examination in Southern Turkey
}

\author{
Muhyittin Temiz Ahmet Aslan Tacettin İnandı Elmir Beshirov Fikret Beyaz
}

Mustafa Kemal University Faculty of Medicine Department of General Surgery, Antakya, Hatay, Turkey

\section{Key Words}

Breast cancer - Diagnosis · Early detection - Epidemiology

\section{Summary}

Background: The aim of this study was to investigate the knowledge, attitudes, and behaviors of female teachers related to breast cancer in Southern Turkey. Materials and Methods: There are almost 5,000 female teachers working in Hatay, Turkey, and we aimed to reach $10 \%$ of this population. Our questionnaire consisted of 14 questions about personal information, 14 questions about knowledge related to breast cancer, and 14 questions about attitudes and behaviors of teachers. Results: In all, 490 female teachers participated in the study. The mean age was 34.6 years, and most were married $(77.1 \%) .62 .9 \%$ of participants reported to have insufficient knowledge about breast cancer. The source of information was newspaper/TV in $84.6 \%$, and medical health care providers in $22.8 \%$. While all of the participants think that early diagnosis of breast cancer is important; $19 \%$ think personal hygiene is protective against breast cancer. Among all the participants, $53.7 \%$ have never practiced breast self-examination (BSE). Of those who practice BSE; $80.6 \%$ practice it as they remember, $12.5 \%$ practice it once a month. $38.4 \%$ of these learned BSE from a doctor, and $38.0 \%$ from TV. The reason for not practicing BSE was underestimation in $46.7 \%$ and lack of knowledge in $37.9 \% .152$ participants had a clinical breast examination (CBE) done, and 145 of these had it done by an expert doctor. A total of 86 participants had undergone mammography, while 67 of the over-40-year-old group had not. Conclusion: $3 / 5$ of the female teachers think that they do not have enough knowledge related to breast cancer. More than half of them do not practice $\mathrm{BSE}$, and only $12.5 \%$ of them practice $\mathrm{BSE}$ regularly.
Schlüsselwörter

Brustkrebs · Diagnose · Früherkennung · Epidemiologie

\section{Zusammenfassung}

Hintergrund: Ziel dieser Studie war die Untersuchung des Wissens, der Einstellung und des Verhaltens von Lehrerinnen in der südlichen Türkei in Bezug auf Brustkrebs. Material und Methoden: Fast 5000 Lehrerinnen sind in Hatay, Türkei tätig. Unser Ziel war es, 10\% dieser Population zu erreichen. Unser Fragebogen enthielt 14 personenbezogene Fragen, 14 Fragen zum Wissen um Brustkrebs und 14 Fragen zu Einstellung und Verhalten der Lehrerinnen. Ergebnisse: Insgesamt nahmen 490 Lehrerinnen an der Studie teil. Das Durchschnittsalter betrug 34,6 Jahre, und die Mehrzahl der Teilnehmerinnen war verheiratet $(77,1 \%) .62,9 \%$ gaben an, über unzureichendes Wissen bezüglich Brustkrebs zu verfügen. Zu den Informationsquellen gehörten Zeitungen/ Fernsehen in $84,6 \%$ der Fälle, und das Gesundheitswesen in $22,8 \%$. Obgleich alle Teilnehmerinnen der Meinung sind, dass Brustkrebsfrüherkennung von Bedeutung ist, glauben $19 \%$, dass Körperpflege vor Brustkrebs schützt. 53,7\% der Teilnehmerinnen haben noch nie eine Brustselbstuntersuchung durchgeführt. 80,6\% derjenigen, die ihre Brust selbst untersuchen, tun dies wann immer sie daran denken, 12,5\% untersuchen sich einmal im Monat. 38,4\% haben die Selbstuntersuchung von einem Arzt gelernt, 38,0\% aus dem Fernsehen. Gründe, keine Selbstuntersuchung durchzuführen, waren Unterschätzung in $46,7 \%$ der Fälle und Unwissen in 37,9\%. 152 Teilnehmerinnen haben in der Vergangenheit eine klinische Brustuntersuchung durchführen lassen. 145 dieser Untersuchungen wurden von einem Spezialisten durchgeführt. Eine Mammographie war bei insgesamt 86 Teilnehmerinnen vorgenommen worden. 67 Frauen über 40 Jahren haben bisher an keiner Mammographie teilgenommen. Schlussfolgerung: 3/5 Lehrerinnen meinen, über unzureichendes Wissen bezüglich Brustkrebs zu verfügen. Mehr als die Hälfte führen keine Brustselbstuntersuchung durch, und nur 12,5\% tun dies regelmäßig.

\begin{tabular}{ll}
\hline KARGER & @ 2008 S. Karger GmbH, Freiburg \\
Fax +497614520714 & Accessible online at: \\
$\begin{array}{l}\text { E-mail Information@Karger.de } \\
\text { www.karger.com }\end{array}$ & www.karger.com/brc
\end{tabular}

\section{KARGER}

www.karger.com
Muhyittin Temiz, MD

Mustafa Kemal University, Faculty of Medicine, Department of General Surgery Bagriyanik Mahallesi

Antakya/Hatay, Turkey

Tel. +90 5327896906

E-mail mhytemiz@yahoo.com 


\section{Introduction}

Breast cancer, the most common type of cancer in women, continues to be one of the main causes of cancer-related death. The prevalence of breast cancer in women is rising. In North America and Western European countries, approximately 1 in every 8 women is reported to suffer from breast cancer, and 1 in every 30 is reported to die from the disease. Although the risk factors for breast cancer have been defined and studied, in more than half of the women suffering from breast cancer these factors were not present $[1,2]$. It was reported that the tumor size and involvement of axillary lymph nodes are among important factors that effect the prognosis of the disease. The increase in tumor size and the involvement of axillary lymph nodes increase the mortality rate. Therefore, early diagnosis and intervention are crucial in decreasing the breast cancer mortality rate [1].

Breast cancer is the most common type of cancer among Turkish women and the second leading cause of death from cancer in Turkey. The corresponding prevalence of breast cancer in Turkey is $24.4[3,4]$.

In the American Cancer Association (ACS) manual of early diagnosis of breast cancer, the following periodic procedures were recommended: for women ages 20 and above monthly breast self-examination (BSE), for women ages 20-40 once every 3 years, and 40 and over once a year clinical breast examination (CBE), starting at age 40 every 1-2 years mammography (MM) [5]. According to the ACS recommendations, women should know how their breasts normally feel and report any breast changes immediately to their health care providers. ACS does not recommend anymore BSE as there is reliable data that breast cancer detection through BSE does not increase survival rates. But, BSE seems to be a viable optional substitute available in rural areas where reaching $\mathrm{CBE}$ and mammograms is difficult. Here, BSE and might still detect breast cancer early enough for treatment which can be offered to prolong women's lives and reduce suffering. For younger women, BSE training is a gateway health promotion behavior which provides women with the knowledge that sets the stage for adherence to CBE and mammography screening guidelines later in life. Screening is related to perceptions of risk, benefit, and barriers through a reasoning process that includes personal and social influences and attitudes $[6,7]$. However, only a few Turkish women do it. According to studies, only $27-39 \%$ of Turkish women have ever performed BSE, but Secginli [4] reported that women performing BSE once a month represented $5.5 \%$ of the population in Istanbul.

The major risk factors for breast cancer in women are certain inherited genetic mutations, a personal or family history of breast cancer, and biopsy-confirmed hyperplasia. Other factors that increase breast cancer risks include a long menstrual history (menstrual periods that started early and/or ended late in life), obesity after menopause, recent use of oral contraceptives, postmenopausal hormone therapy, never having had child-
Table 1. Demographic characteristics of the study participants

\begin{tabular}{|c|c|}
\hline & $\begin{array}{l}\text { Participants, } \\
\text { n (\%) }\end{array}$ \\
\hline \multicolumn{2}{|l|}{ Marital status } \\
\hline Married & $378(77.1)$ \\
\hline Single & $100(20.4)$ \\
\hline Divorced & $12(2.4)$ \\
\hline \multicolumn{2}{|l|}{ Work place } \\
\hline City & $209(42.7)$ \\
\hline County & $89(18.2)$ \\
\hline Town & $91(18.6)$ \\
\hline Village & $101(20.6)$ \\
\hline \multicolumn{2}{|l|}{ Presence of breast related complains } \\
\hline Severe breast pain & $67(13.7)$ \\
\hline Mass in breast & $20(4)$ \\
\hline Nipple discharge & $2(0.4)$ \\
\hline Milk discharge & $2(0.4)$ \\
\hline Breast cancer & $1(0.2)$ \\
\hline \multicolumn{2}{|l|}{ Breast pain } \\
\hline Menstruation-related pain & $174(35.5)$ \\
\hline Continuous pain & $14(2.9)$ \\
\hline \multicolumn{2}{|l|}{ Sufficient knowledge related to breast cancer } \\
\hline Yes & $182(37.1)$ \\
\hline No & $308(62.9)$ \\
\hline \multicolumn{2}{|l|}{ Source of information } \\
\hline News-TV & $265(54)$ \\
\hline News-TV-health personnel and... & $140(28.6)$ \\
\hline Health personnel & $28(5.7)$ \\
\hline Health personnel- news-TV and... & $90(18.4)$ \\
\hline Medical books/publications & $5(1)$ \\
\hline Medical books/publications-news-TV-health personnel & $48(9.8)$ \\
\hline Online resources & $13(2.7)$ \\
\hline Online resources- news-TV-health personnel and... & $40(8.2)$ \\
\hline No information & $33(6.7)$ \\
\hline \multicolumn{2}{|l|}{ Biopsy } \\
\hline Once & $23(4.7)$ \\
\hline Twice & $7(1.4)$ \\
\hline
\end{tabular}

ren or having the first child after age 30 , ethnicity characteristics, exposure to radiation $[6,7]$. Cultural factors such as beliefs, attitudes, and knowledge about cancer are also known to vary dramatically by race, and the importance of these cultural factors is increasingly recognized. Women who hold any of the culturally derived folk beliefs, fundamentalist religious beliefs, or beliefs about relations with men or fatalism were all significantly more likely to present with late-stage disease [8]. This study aimed to investigate the knowledge, attitudes, and behaviors of female teachers related to breast cancer in Hatay, Turkey.

\section{Methods}

There are almost 5,000 female teachers working in Hatay and we aimed to reach $10 \%$ of this population. Our questionnaire consisting of 14 questions about personal information, 14 questions about knowledge related to breast cancer, and 14 questions about attitudes and behaviors of teachers, was filled out by 512 female teachers between March 2005 and August 2005. The 22 questionnaires which were not filled completely were 
Table 2. Knowledge characteristics of the study participants

Participants, $\mathrm{n}(\%)$

Breast cancer-related findings

Mass

Mass-pain-wound not healing and...

$184(37.6)$

237 (48.4)

Pain

$22(4.5)$

$142(29)$

$97(19.8)$

$65(13.3)$

$168(34.3)$

$64(13)$

Pain in arm-mass-pain

Risk of developing breast cancer compared to other women

Less

Same

Higher

$88(18)$

$196(40)$

$41(8.4)$

Don't know

Risk of those with family history of breast cancer

Higher

Same

$385(78.6)$

$25(5.1)$

$29(5.9)$

$51(10.4)$

Don't know

The preventive effect of personal hygiene

High

Same

None

Don't know

The effect of breast feeding on cancer

Reduces

Same

Increases

Don't know

The effect of nulliparity

Reduces

Same

Increases

Don't know

$86(17.6)$

$104(21.2)$

$153(31.2)$

147 (30)

$386(78.8)$

$36(7.3)$

$3(0.6)$

65 (13.3)

$20(4.1)$

79 (16.1)

274 (55.9)

65 (23.9)

The effect of early delivery

Reduces

Same

Increases

Don't know

$51(10.4)$

$108(22.0)$

$76(15.5)$

255 (23.9)

The effect of short term oral contraceptive use

Reduces

Same

37 (7.6)

$92(18.8)$

$59(12.0)$

302 (61.6)

Don't know

$23(4.7)$

$27(5.5)$

$120(24.5)$

$320(65.3)$

244 (49.8)

203 (41.4)

$43(8.9)$

Don't know

Mammography is

Helpful

Harmful

$386(78.7)$

$38(7.8)$

$3(0.6)$

63 (12.9)
Table 2. Continued

Participants,

n (\%)

The first thing you think about mammography

Early diagnosis

$398(81.2)$

Fear of cancer

$31(6.3)$

Having radiation

$27(5.5)$

Pain

9 (1.8)

$25(5.1)$

After what age can mammography be applied routinely

Any age

After 20

37 (7.6)

36 (7.3)

After 30

143 (29.2)

After 40

204 (41.6)

After 50

5 (1.0)

Don't know

65 (13.3)

excluded from the study; 490 were included. The results were analyzed using the SPSS 13.0 program (SPSS Inc, Chicago, IL, USA). Personal information questions included marital status, working school, having complaints related to the breast, alcohol intake, smoking and others. Questions measuring the knowledge related to breast cancer were the first signs of breast cancer, the role of nulliparity, not breast feeding, and the use of oral contraceptives. The questions about behaviors were about the frequency of BSE and CBE, from who they were learnt, the reason why they were not perform, history of undergoing MM, the frequency of MM.

\section{Results}

In all, 490 female teachers participated in the study. The mean age of the respondents was $34.6+/-7.3$ years (22-55), and most were married $(77.1 \%)$. Of the participants, $42.7 \%$ were working in the city center, $18.2 \%$ were in the county, $18.6 \%$ were in town, and $20.6 \%$ were in village schools. $62.9 \%$ participants have reported to have insufficient knowledge about breast cancer. 45.9 of the teachers working in the city center had enough knowledge, while only $29.2 \%$ of the teachers working in the county reported to have enough knowledge. The rate of the teachers with sufficient knowledge in town and villages were $(30.8 \%)$ and $(31.7 \%)$, respectively. When the groups were compared with each other, the number of teachers with sufficient knowledge was statistically significantly higher between teachers in the city center. $(\mathrm{p}=0.00$; table 1$)$.

The source of information was newspaper/TV in $84.6 \%$, medical health care providers in $22.8 \%$. The answer to the question about the most common finding related to breast cancer was growth on the breast in $81.8 \%$ whereas nipple discharge was in $37.9 \%$. While all of the participants think that early diagnosis of breast cancer is important; $19 \%$ of them think personal hygiene is protective against breast cancer. Among all the participants, $53.7 \%$ have never practiced BSE. Of the ones who have, $80.6 \%$ practice it as they remembered, $12.5 \%$ practice it once a month. $38.4 \%$ of these learned BSE from a doctor, and $38.0 \%$ from TV. The reason for not practicing BSE was unde- 
Table 3. Breast selfexamination (BSE), clinical breast examination (CBE)

\begin{tabular}{|c|c|}
\hline & $\begin{array}{l}\text { Participants, } \\
\mathrm{n}(\%)\end{array}$ \\
\hline \multicolumn{2}{|l|}{ BSE } \\
\hline Yes & $263(53.7)$ \\
\hline No & $227(46.3)$ \\
\hline \multicolumn{2}{|l|}{ Frequency of BSE } \\
\hline As I remember & $212(43.3)$ \\
\hline Once a month & $33(6.7)$ \\
\hline Once a week & $12(2.4)$ \\
\hline Once every 3 months & $2(0.4)$ \\
\hline Once every 6 months & $2(0.4)$ \\
\hline \multicolumn{2}{|l|}{ Training sources of BSE } \\
\hline Physician & $101(20.6)$ \\
\hline TV & $100(20.4)$ \\
\hline Nurse & $27(5.1)$ \\
\hline Friend & $20(4.3)$ \\
\hline Medical books/publication & $16(4.3)$ \\
\hline \multicolumn{2}{|l|}{ Reason of not conducting BSE } \\
\hline Underestimation & $106(21.6)$ \\
\hline Lack of knowledge & $86(17.6)$ \\
\hline Fear of finding growth & $14(2.9)$ \\
\hline Lack of complaints & $9(1.8)$ \\
\hline Not finding it necessary & $8(1.6)$ \\
\hline Waste of time & $4(0.8)$ \\
\hline Being too young & $2(0.4)$ \\
\hline \multicolumn{2}{|l|}{ Having CBE } \\
\hline Yes & $152(31)$ \\
\hline No & $338(69)$ \\
\hline \multicolumn{2}{|l|}{ CBE performer } \\
\hline Specialist & $145(29.6)$ \\
\hline GP & $5(1)$ \\
\hline Nurse & $2(0.4)$ \\
\hline \multicolumn{2}{|l|}{$\mathrm{CBE}$ frequency } \\
\hline Only once & $83(16.9)$ \\
\hline Once a year & $37(7.6)$ \\
\hline Once in 2 years & $28(5.7)$ \\
\hline Once every 6 months & $12(2.4)$ \\
\hline \multicolumn{2}{|l|}{ Reason for not having $\mathrm{CBE}$} \\
\hline Carelessness & $206(42)$ \\
\hline Lack of knowledge & $59(12)$ \\
\hline Think it is unnecessary & $20(4.1)$ \\
\hline Fear of finding growth & $19(3.9)$ \\
\hline No need & $16(3.3)$ \\
\hline No complaints & $16(3.3)$ \\
\hline Waste of time & $2(0.4)$ \\
\hline
\end{tabular}

restimation in $46.7 \%$, lack of knowledge in $37.9 \%$, and fear of finding a growth in $6.1 \%$ (table 2 ).

In our study, 152 participants (31\%) had CBE done, and 145 of these had it done by an expert doctor while 5 had it done by a GP. 95.4\% (145) had their breast examination done by a specialist and $1.0 \%$ (5) by a physician at least once. The reason for not having CBE was underestimation in $60.9 \%$, lack of knowledge in $17.4 \%$, thinking that it was unnecessary in $5.9 \%$ of the participants. The reason not to do CBE was carelessness in $60.9 \%$, insufficient knowledge in $17.4 \%$, not having any complaints and feeling no need in $11.9 \%$, believing that it had no benefit in $5.1 \%$, and the fear of finding a growth in $4.7 \%$ (table 3).
In the 18-34-year-old group, 11 participants, in the 35-39-yearold group 20 participants, in the 40-49-year-old group 45 participants, 50-55-year-old group 11 participants (total of 86 (17.6\%) participants) had a MM. 48 of these had only one, 18 had it once a year, 18 had it once in 2 years. 33 had MM because of having complaints, 33 voluntarily for control reasons and under doctor control, and 20 had it based on medical advice. The reason not to undergo MM was 'carelessness' in $70.1 \%$ (47), 'having no information' in 7.5\% (5), 'being afraid of finding a growth' in $7.5 \%$ (5) 'thinking that it is not essential' in $7.5 \%$ (5), and 'having no complaints' in 6\% (4).

The mean age in the group of women who claimed to have enough information was 35.8 years and 33.8 years in the other. This difference was significant (0.03). There was a statistical significance in the sufficiency of the knowledge of married teachers in contrast to singles and of the over-40year-old group when compared to $<40$-year-old groups. The average age of the BSE performer group was 36.4 years while it was 32.4 years in the none-performing group. This difference was statistically significant (0.00). The average age in the BCE performed group was 38.3 years while it was 32.8 years in the other. This was significant (0.00). Similarly, there was a significance in performing BSE and having $\mathrm{CBE}$ in the married vs. single, over-40-year-old group when compared to $<40$-year-old groups (BSE 0.00-0.00-0.00-0,006 and CBE $0.00-0.00-0.00-0.00)$.

\section{Discussion}

Teachers play an important role in the education of the population. Their knowledge about breast cancer is estimated to effect the behavior and attitudes of their education population. This study was conducted to assess the knowledge, behavior, and attitudes of female teachers in Hatay, southern Turkey which is expected to effect their student and parent population.

Breast cancer has a lot of effect on women health. The incidence of breast cancer shows differences between countries. The incidence is at its minimum in Asia whereas it is at its maximum in the USA and South America. In Asian countries, the incidence is increasing because of the increasing Western life style [9]. The incidence is increasing in our country too, but the reports of Health Ministry do not reflect the true rates. Data of the government hospitals, university hospitals, and private hospitals were kept separately, but were united recently so the real incidence will be known in the next years.

A majority of the sample $(76.6 \%)$ reported that they had heard or read about breast cancer, but only $56.1 \%$ of them had sufficient knowledge of it. TV/ radio programs were identified as the main source of information on breast cancer by $39.3 \%$ of the participants. Health professionals were mentioned as a source of information by $23.4 \%$ of the sample [7]. Unmarried women were more likely not to use breast cancer 
Table 4. Mammography (MM)

\begin{tabular}{lcc}
\hline & $\begin{array}{l}\text { Participants, } \\
n(\%)\end{array}$ & $\begin{array}{l}\text { In > 40-group, } \\
\%\end{array}$ \\
MM & & \\
Yes & $86(17.6)$ & \\
No & $404(82.4)$ & \\
MM over 40 years old & $56(45.5)$ & \\
Yes & $67(54.5)$ & \\
No & & \\
MM frequency & $48(9.8)$ & 20.9 \\
Only once & $18(3.7)$ & 20.9 \\
Once a year & $18(3.7)$ & 2.3 \\
Once in 2 years & $2(0.4)$ & 70.1 \\
Once in 6 months & $47(38.2)$ & 7.5 \\
Reason for not having MM after 40 years old (n = 67) & 7.5 \\
Carelessness & $5(4)$ & 7.5 \\
Lack of knowledge & $5(4)$ & 5.9 \\
Fear of finding growth & $5(4)$ & 1.5 \\
Thinking it is unnecessary & $4(3.3)$ & \\
Having no complaints & $1(0.8)$ & \\
Pain & &
\end{tabular}

screening [11]. Also, community believes are important in behaviors. Most of the Samoan women living in Hawai do not practice BSE or do not allow CBE and believe that cancer means death and is not curable [12]. In a study performed in Sweden, $70 \%$ of the women aged between $25-80$ years practiced BSE regularly [13]. In a study performed in Hong-Kong, less than $50 \%$ of the participants practiced BSE monthly [14]. In studies of community samples of diverse women groups conducted in the United States, the rates of performing monthly BSE ranged from 29 to $63 \%$ [10]. Dundar et al. [7] performed a study including women living in the western rural areas of Turkey. According to the women's responses, $23.4 \%$ of them had no knowledge about breast cancer, $27.9 \%$ had no concept of BSE. In a similar study of teachers working in Tahran, $6 \%$ of the participants had practiced BSE regularly, 37\% had practiced BSE rarely, and $57 \%$ had never practiced BSE [9]. At least $53 \%$ of our participants had performed BSE at least once whereas only $6.7 \%$ of them perform BSE regularly once a month. In women living in Iran, the most common reasons for not practicing BSE and CBE were not having any information in $34 \%$, and seeing no need in $36 \%$. In our study, the reasons were underestimation in $21 \%$ and not having enough knowledge in $17 \%$. The reasons for not having CBE was carelessness in $42 \%$ and inadequate knowledge in $12 \%$, and only $1 / 3$ women had CBE. Previous studies performed in Turkey reported that the level of cancer knowledge of Turkish population was not adequate, the rate of performing BSE is low, and most of the women do not know how to examine their breasts correctly. According to this, there is a need for meetings and conferences for educating women about breast cancer. On the other hand, Canadian Task Force on Preventive Health Care reported that BSE procedure could be more harmful than beneficial and stated that as a cancer screening technique BSE should be taught to women ages 40-69 as a routine procedure [15].

Dundar et al. [7] reported that $89.3 \%$ of women had never had an MM and $75.0 \%$ had never had CBE. $27.9 \%$ of the women participants, expressed no previous knowledge of MM. Only $5.1 \%$ of them had an MM annual or over a 2-year period [7]. In our study, $17 \%$ of the participants had mammography but when specified to the over-40-year-old group, $48 \%$ had an MM. Our study population consisted of female teachers whose socioeconomic class is expected to be higher. Thus, the rates of sufficient knowledge and having an MM might have been higher in our study (table 4).

Barriers to mammography screening identified in the literature include inconvenience, worry, embarrassment, fear of radiation or pain, belief that mammography is unnecessary in the absence of symptoms, and lacking knowledge of recommended guidelines [16]. In our study, the most reported reason for not having breast examination was carelessness in $70 \%$, but also lack of knowledge, fear of finding a growth, not thinking it is necessary were among other reasons. This laxity can be corrected via explaining the usefulness of $\mathrm{MM}$ and motivation of the health care providers.

\section{Conclusion}

$3 / 5$ of the female teachers think that they do not have enough knowledge related to breast cancer. More than half of them do not practice BSE, and only $6.7 \%$ of them practice BSE regularly. It was concluded that teachers need education about breast cancer.

\section{References}

1 Rimer BK Harris JR, Lippman ME, Morrow M, Hellman S: Breast Cancer Screening. Diseases of the Breast. Philadelphia, Lippincott Co, 1996.

2 Humphrey LL, Helfand M, Chan BK, Woolf SH: Breast cancer screening: a summary of the evidence for the U.S. Preventive Services Task Force. Ann Intern Med 2002;137:347-60.

3 Ministry of Health: The most frequent ten cancers in females in Turkey, 1999 (online breast cancer resources center). Available at www.saglik.gov.tr/ extras/statistics.
4 Secginli S, Nahcivan NO: Reliability and validity of the breast cancer screening belief scale among Turkish women. Cancer Nurs 2004;27:287-94.

5 American Cancer Society: Cancer Facts and Figures 1999. Atlanta, GA, American Cancer Society, 1999, pp. 1-36.

6 American Cancer Society: Cancer Facts and Figures 2005. http://www.cancer.org/docroot/STT/ content/STT_1x_Cancer_Facts_Figures_2005.asp.
7 Dundar PE, Ozmen D, Ozturk B, Haspolat G, Akyildiz F, Coban S, Cakiroglu G: The knowledge and attitudes of breast self-examination and mammography in a group of women in a rural area in western Turkey. BMC Cancer 2006;6:43.

8 Lannin DR, Mathews HF, Mitchell J, Swanson MS, Swanson FH, Edwards MS: Influence of socioeconomic and cultural factors on racial differences in late-stage presentation of breast cancer. JAMA 1998;279:1801-7. 
9 Jarvandi S, Montazeri A, Harirchi I, Kazemnejad A: Beliefs and behaviours of Iranian teachers toward early detection of breast cancer and breast self-examination. Public Health 2002;4:245-9.

10 Secginli S, Nahcivan NO: Factors associated with breast cancer screening behaviours in a sample of Turkish women: a questionnaire survey. Int J Nurs Stud 2006;43:161-71.

11 Siahpush M, Singh GK: Sociodemographic variations in breast cancer screening behavior among Australian women: results from the 1995 National Health Survey. Prev Med 2002;35:174-80.

12 Ishida DN, Toomata-Mayer TF, Braginsky NS: Beliefs and attitudes of Samoan women toward early detection of breast cancer and mammography utilization. Cancer 2001;91:262-6.

13 Persson K, Svensson PG, Ek AC: Breast self-examination: an analysis of self-reported practice. J Adv Nurs 1997;25:886-92.

14 Fung SY: Factors associated with breast self-examination behaviour among Chinese women in Hong Kong. Patient Educ Couns 1998;33:233-43.

15 Baxter N: Preventive health care, 2001 update: should women be routinely taught breast self-examination to screen for breast cancer? CMAJ 2001; 164:13.

16 Rimer BK, Keintz MK, Kessler HB, Engstrom PF, Rosan JR: Why women resist screening mammography: patient-related barriers. Radiology 1989; 172:243-6. 